\title{
AULAS ON-LINE NO CONTEXTO DA EDUCAÇÃO SUPERIOR EM TEMPOS DE PANDEMIA
}

\author{
Karen Graziela Weber Machado \\ Pontifícia Universidade Católica do Rio Grande do Sul - PUCRS \\ Felipe Sereno Soso \\ Pontifícia Universidade Católica do Rio Grande do Sul - PUCRS \\ Adriana Justin Cerveira Kampff \\ Pontifícia Universidade Católica do Rio Grande do Sul - PUCRS
}

\begin{abstract}
Resumo
O presente estudo tem por objetivo analisar o que dizem os organismos multilaterais, associações internacionais, e outras instituições de referência para a educação sobre as estratégias para a reorganização da Educação Superior, no contexto local (brasileiro) e global (mundial), em face da pandemia do novo coronavírus. A metodologia adotada é de caráter qualitativo exploratório, mediante a realização de pesquisa bibliográfica. $\mathrm{O}$ ponto de partida foi a busca por documentos nos sites da Associação Internacional de Universidades (IAU), da Organização das Nações Unidas para a Educação, a Ciência e a Cultura (UNESCO), do Instituto Internacional para a Educação Superior na América Latina e Caribe (IESALC), da Organização para a Cooperação e Desenvolvimento Econômico (OCDE), do Banco Mundial, do Ministério da Educação (MEC), da Coordenação de Aperfeiçoamento de Pessoal de Nível Superior (CAPES), entre outros. Os documentos analisados apontam diversas estratégias para auxiliar na execução das aulas remotas emergenciais, e estabelecem alguns princípios que devem guiar a continuidade das atividades pedagógicas, dentre eles estão: o desenvolvimento de projetos pedagógicos inclusivos e equitativos, a capacitação docente para atuar em plataformas virtuais, e o suporte discente para engajar os estudantes e reduzir a sensação de isolamento.
\end{abstract}

Palavras-chave: Educação Superior, Educação On-line, Ensino Remoto Emergencial, Pandemia da COVID-19.

\begin{abstract}
The present study aims to analyze what multilateral organizations, international associations and other reference institutions for education say about the strategies for the reorganization of Higher Education, in the local (Brazilian) and global (global) context, facing the coronavirus pandemic. The adopted methodology is of qualitative exploratory nature, by means of bibliographic research. The starting point was the search for documents on the websites of the International Association of Universities (IAU), the United Nations Educational, Scientific and Cultural Organization (UNESCO), the International Institute for Higher Education in Latin America and the Caribbean (IESALC), the Organization for Economic Co-operation and Development (OECD), the World Bank, the Ministry of Education (MEC), the Coordination for the Improvement of Higher Education Personnel (CAPES), among others. The analyzed documents point out several strategies to assist the execution of emergency remote teaching, and establish some principles that should guide the continuity of pedagogical activities, among them: the development of inclusive and equitable pedagogical projects, the training of teachers to work on virtual platforms, and student support to engage them and reduce the feeling of isolation.
\end{abstract}

ISSN 1645-1384 (online) www.curriculosemfronteiras.org 
Keywords: Higher Education, On-line Education, Emergency Remote Teaching, COVID-19 pandemic. 


\section{Introdução}

Segundo o portal da Coordenação de Aperfeiçoamento de Pessoal de Nível Superior CAPES (2020) a pandemia do novo coronavírus (a doença do coronavírus - Coronavirus Disease - COVID-19) tem se propagado pelo mundo. Este novo vírus foi descoberto em 31 de dezembro de 2019, na China. O vírus provoca sintomas iniciais semelhantes a um resfriado, porém se agrava rapidamente, causando infecções respiratórias, podendo ser fatal. A melhor maneira de combater a pandemia se refere a buscar manter-se informado e adotar medidas adequadas de prevenção.

De acordo com o site da UNESCO ${ }^{1}$ (2020a) sobre a Coalizão Global da Educação, na atualidade são milhões de estudantes pelo mundo sendo impactados pelo fechamento de universidades devido ao surto da COVID-19. Neste sentido, é importante que esta iniciativa possa contribuir para facilitar as oportunidades de aprendizagem inclusiva durante este período de interrupção educacional súbita e sem precedentes. É imprescindível o investimento na aprendizagem a distância para reduzir a intensidade da interrupção imediata gerada pela COVID-19 e estabelecer abordagens para desenvolver mais sistemas educacionais abertos e flexíveis futuramente.

Desse modo, compreende-se que a pandemia do novo coronavírus tem causado impactos profundos na educação, assim como em outros setores da sociedade, a nível mundial. Uma das recomendações de prevenção à COVID-19 do Ministério da Saúde brasileiro é permanecer em casa, evitando ao máximo a circulação nas ruas e locais fechados que favoreçam o contato aproximado com outras pessoas. A Organização Pan-Americana da Saúde - OPAS (2020) recomenda evitar contato próximo entre pessoas, inclusive com membros da família que não habitam na mesma residência, mantendo a distância mínima de dois metros.

As orientações dos órgãos de saúde para o distanciamento social impossibilitaram a realização de atividades que envolvem aglomeração de pessoas, o que inclui a oferta da Educação Superior em seu formato presencial. Isto implica dizer que a praxe pedagógica, antes exercida nos locais onde situam-se as Instituições de Ensino Superior (IES), precisou ser transferida para o ambiente doméstico, e desse modo, para dar continuidade ao processo de ensino e aprendizagem, as aulas têm sido desenvolvidas remotamente.

Esta mudança abrupta e inesperada da modalidade educativa fez com que muitos professores se deparassem com o desafio inédito de organizar e executar aulas através de meios digitais. Da mesma forma, estudantes tiveram que se adaptar a ambientes virtuais para que fosse possível prosseguir com o desenvolvimento de suas aprendizagens. Referente a isso, Morgado, Souza e Pacheco (2020) destacam que na atualidade a educação tem se deparado com inúmeros desafios resultantes da pandemia da COVID-19, dentre eles pode-se citar a mudança na forma de realizar o trabalho docente, pois o confinamento social e as medidas de emergência geradas por essa crise fizeram com que o ensino presencial passasse para o ensino on-line.

Corroborando com a questão mencionada, Pontes e Rostas (2020) relatam que o surgimento deste novo vírus impôs à sociedade alterações no modo de interagir, gerando 
novas atribuições aos professores, as quais ultrapassam o domínio de conteúdos e estratégias pedagógicas. Ao docente, em tempo recorde, foi exigida a responsabilidade de inteirar-se sobre ferramentas on-line e adequar-se ao ensino remoto, buscando despertar o interesse dos estudantes, havendo necessidade de adaptar o conteúdo e as rotinas para um modelo que se distingue do presencial, o que pode suscitar o desenvolvimento de experiências pedagógicas síncronas e assíncronas, além de estar disponível para participar de conferências virtuais em horários que podem ser diferentes em relação ao seu trabalho presencial. Diante da realidade apresentada neste momento de excepcionalidade, pode-se afirmar que estão ocorrendo modificações na forma de desenvolver o trabalho pedagógico dos docentes e de aprender dos estudantes, os quais pertenciam ao sistema presencial educacional superior. Nesta perspectiva, considerou-se necessária a elaboração desta pesquisa, cujo objetivo é analisar o que dizem documentos legais brasileiros, organismos multilaterais e instituições responsáveis pela educação sobre as estratégias para a reorganização da Educação Superior no contexto local (brasileiro) e global (mundial).

\section{Referencial teórico}

A interrupção das atividades presenciais nas instituições de ensino provocou uma rápida adoção de ambientes virtuais para o seguimento do trabalho pedagógico. Essa transposição para modelos não-presenciais tem sido confundida com a modalidade de Educação a Distância $(\mathrm{EaD})$, porém as diferenças são explícitas do desenvolvimento à execução.

Hodges et al. (2020) refletem a questão comparando um projeto de $\mathrm{EaD}$ e as aulas que foram projetadas para execução presencial, mas que no momento estão sendo realizadas remotamente, aulas que os autores sugerem que sejam chamadas de Emergency Remote Teaching - ERT (Ensino Remoto Emergencial - ERE).

"Ao contrário das experiências planejadas desde o início e projetadas para serem on-line, o Ensino Remoto Emergencial é uma mudança temporária da modalidade de instrução para um modelo de ensino alternativo devido a circunstâncias de crise. Isso envolve o uso de soluções de ensino totalmente remotas para instrução ou educação que, caso contrário, seriam ministradas pessoalmente ou como cursos combinados ou híbridos e que retornarão a esse formato assim que a crise ou emergência tiver diminuído" (HODGES, 2020, tradução nossa).

A necessidade emergente de transferir as aulas para plataformas virtuais surge do ímpeto de evitar a paralisação completa das atividades pedagógicas. Tal demanda contradiz o tempo e o esforço dedicados ao desenvolvimento de cursos à distância de qualidade, que exigem tempo maior de preparação até sua efetiva execução. O ensino remoto emergencial não deve ser visto como uma solução de longo prazo, mas como uma alternativa temporária a um problema imediato (Hodges et al, 2020). 
No mesmo sentido, Behar (2020) argumenta que enquanto a Educação a Distância exige a elaboração de uma arquitetura pedagógica específica, concebida para que estudantes, tutores e professores possam desenvolver atividades educativas em tempos e lugares diversos, o Ensino Remoto Emergencial foi adotado de forma temporária por instituições educacionais do mundo inteiro para que as atividades pedagógicas não fossem interrompidas.

No ERE, a aula ocorre num tempo síncrono (seguindo os princípios do ensino presencial), com videoaula, aula expositiva por sistema de webconferência, e as atividades seguem durante a semana no espaço de um ambiente virtual de aprendizagem (AVA) de forma assíncrona. A presença física do professor e do aluno no espaço da sala de aula presencial é "substituída" por uma presença digital numa aula online, o que se chama de 'presença social'. Essa é a forma como se projeta a presença por meio da tecnologia. E como garanti-la? Identificando formas de contato efetivas pelo registro nas funcionalidades de um AVA, como a participação e discussões nas aulas online, nos feedbacks e nas contribuições dentro do ambiente (Behar, 2020, s/p).

Apesar da maioria dos docentes não estar capacitada para desenvolver aulas não presenciais, eles estão sendo desafiados a reinventar suas práticas. As circunstâncias trazidas pela pandemia fizeram com que, imediatamente, o planejamento pedagógico para o ano letivo de 2020 tivesse que ser reformulado. Para a autora: "Podemos dizer que o que iria talvez ocorrer na educação em uma década acabou acontecendo de forma 'emergencial' em um, dois ou três meses", e que nesse momento de transição é preciso "organização, paciência, permitir-se ter tempo de adaptação, errar, pedir ajuda, compartilhar!” (Behar, 2020, s/p).

Em reunião realizada no dia 02 de abril de 2020, o Comitê Gestor dos Objetivos para o Desenvolvimento Sustentável (ODS) apresentou algumas recomendações de suporte a uma educação de qualidade. O texto estabelece que os princípios de inclusão e equidade devem guiar todas as respostas educacionais à COVID-19. Os governos devem renovar seu compromisso em "não deixar nenhum aprendiz para trás" (UNESCO, 2020d, p. 1, tradução nossa), de forma a prevenir que as diferenças socioeconômicas, digitais e educacionais aumentem em tempos de crise, e assegurar igualdade de oportunidades a todos, especialmente aos mais vulneráveis e marginalizados, o que inclui refugiados.

Outra preocupação do Comitê é com os professores e sua importante atuação durante a pandemia. Esses profissionais se encontram pressionados para manter o ritmo e a qualidade de suas práticas em um contexto totalmente novo. As recomendações à administração pública são de priorizar a segurança, a saúde e o bem-estar dos docentes, preservando seus empregos e direitos fundamentais, para que com suporte informacional possam fazer uso de plataformas colaborativas e desenvolver práticas pedagógicas adequadas aos contextos em que se inserem.

A atuação dos Estados é colocada como primordial na execução de ações de enfrentamento a essa pandemia. Projetos de médio e longo prazo devem ser colocados em pauta para minimizar os impactos de um possível cenário de recessão econômica mundial que traga cortes de investimentos na educação. Por isso, o Comitê Gestor "convida todos os 
parceiros a unirem forças para garantir que o aprendizado continue para todos e que nossos sistemas educacionais saiam dessa crise mais fortes, mais resistentes, inovadores, responsivos e inclusivos" (UNESCO, 2020d, p. 1, tradução nossa).

Sendo assim, diante da atual conjuntura compreende-se que é fundamental refletir e debater sobre as estratégias sugeridas por organismos multilaterais e instituições responsáveis pela educação, incluindo as alternativas que têm sido adotadas por unidades educativas, pois isto poderá favorecer o compartilhamento de informações e a troca de ideia entre os profissionais da educação, questões estas essenciais para que o processo educativo continue sendo desenvolvido com qualidade.

\section{Metodologia}

O presente trabalho tem por objetivo analisar o que dizem documentos legais brasileiros, organismos multilaterais e instituições vinculadas à educação sobre as estratégias para a reorganização da Educação Superior no contexto local (brasileiro) e global (mundial). Este estudo é caracterizado como uma pesquisa exploratória com abordagem qualitativa.

Segundo Yin (2016), a pesquisa qualitativa caracteriza-se por permitir a elaboração de estudos aprofundados a respeito de uma ampla variedade de tópicos, e oferecer maior liberdade para selecionar temas de interesse, enquanto outros métodos de pesquisa tendem a ser limitados. Pode-se afirmar que tal tipo de pesquisa se tornou uma forma aceitável, se não dominante, em diversas áreas acadêmicas e profissionais.

Consequentemente, o grande número de estudantes e estudiosos que desenvolvem estudos qualitativos pode fazer parte de distintas disciplinas de ciências sociais aplicadas, como sociologia, antropologia, ciência política ou psicologia, ou variadas profissões como, por exemplo, as relacionadas à educação, à administração, à enfermagem, ao planejamento urbano e à avaliação de programas em diversas esferas de atuação. Em qualquer dessas áreas, a pesquisa qualitativa tem representado uma maneira atraente e produtiva de realizar pesquisa (Yin, 2016).

De acordo com Gil (2018) toda pesquisa científica tem seus objetivos, os quais são diferentes dos objetivos de qualquer outra. Apesar disso, em relação aos objetivos mais gerais, ou propósitos, as pesquisas podem ser classificadas em três tipos, isto é, exploratórias, descritivas e explicativas.

Para o autor referido, as pesquisas exploratórias têm a finalidade de proporcionar maior familiaridade com a problemática do estudo, com vistas a torná-lo mais explícito ou a construir hipóteses. Seu planejamento tende a ser muito flexível, pois interessa considerar os mais diversificados aspectos relativos ao fato ou fenômeno estudado. A coleta de dados pode ser realizada de diversas formas, mas geralmente envolve levantamento bibliográfico e análise que estimule a compreensão.

A pesquisa bibliográfica é produzida com base em material já publicado, o que pode incluir material impresso ou disponibilizado pela Internet, ou seja, livros, revistas, jornais, teses, dissertações, anais de eventos científicos, dentre outros. A pesquisa bibliográfica é 
vantajosa, devido ao fato de possibilitar ao investigador a cobertura de uma gama de fenômenos muito mais ampliada do que em relação àquela que poderia pesquisar diretamente (Gil, 2018).

Nesta perspectiva, o procedimento adotado para o desenvolvimento da coleta de dados se refere à busca em sites de organismos multilaterais, órgãos educacionais, legislação/decretos nacionais e outras instituições vinculadas a temas da educação, visando encontrar documentos relevantes sobre a temática proposta, tendo em vista o objetivo da pesquisa.

Em suma, foram selecionados documentos que tratam da educação no contexto da pandemia da COVID-19, localizados a partir da pesquisa junto aos repositórios dos seguintes organismos: Associação Internacional de Universidades (IAU), Organização das Nações Unidas para a Educação, a Ciência e a Cultura (UNESCO), Organização para a Cooperação e Desenvolvimento Econômico (OCDE), Instituto Internacional para a Educação Superior na América Latina e Caribe (IESALC), Banco Mundial, Educause, Associação Europeia de Educação Internacional (EAIE), Associação Brasileira de Educação Internacional (FAUBAI) e outros órgãos educacionais brasileiros, como o Ministério da Educação (MEC) e a Coordenação de Aperfeiçoamento de Pessoal de Nível Superior (CAPES). Estes portais foram escolhidos devido ao fato de abordarem assuntos relevantes a respeito da questão norteadora desta pesquisa, bem como as estratégias para a reorganização da Educação Superior no contexto local (brasileiro) e global (mundial), diante aos desafios trazidos pela pandemia do novo coronavírus.

\section{Discussão e resultados}

Nesta seção o ponto de partida para o desenvolvimento das discussões se dará por meio dos organismos multilateriais - organizações internacionais - os quais se referem a entidades constituídas por diversos governos nacionais, tendo por intuito promover determinado objetivo comum aos países membros para o pleno desenvolvimento das variadas áreas de atividade humana, envolvendo questões referentes à política, economia, educação, saúde, segurança, dentre outros.

Neste sentido, serão abordadas em seguida algumas contribuições dos organismos multilaterais, a saber: a UNESCO, a OCDE, o Banco Mundial e a IESALC, para o processo educacional no contexto pandêmico. Posteriormente, será referenciada a Associação Internacional de Universidades (IAU), bem como outros sites relevantes para a elaboração desta pesquisa que foram apresentados pela IAU, ou seja, a Educause, a Associação Europeia de Educação Internacional (EAIE), e a Associação Brasileira de Educação Internacional (FAUBAI). Por fim, serão apresentados pontos importantes ressaltados por órgãos do sistema educacional brasileiro: o Ministério da Educação (MEC) e a Coordenação de Aperfeiçoamento de Pessoal de Nível Superior (CAPES), tendo a finalidade de responder o objetivo proposto deste estudo. 
Em virtude dos desafios impostos à educação devido à pandemia da COVID-19, a UNESCO lançou uma publicação contendo orientações sobre práticas educacionais abertas durante o período de pandemia, a qual foi intitulada como "Guidance on Open Educational Pratices during COVID-19 pandemic" (Orientações sobre práticas educacionais abertas durante a pandemia da COVID-19). Esta publicação tem por objetivo destacar as implicações do uso de Práticas Educacionais Abertas (PEA) nos resultados da aprendizagem. O documento é composto de exemplos ilustrativos, abordagens inovadoras para a utilização dos recursos e práticas educacionais abertas em todo o mundo durante a pandemia do coronavírus. Tais experiências estão relacionadas com cinco (5) áreas da recomendação sobre Recursos Educacionais Abertos (REA) da UNESCO: (1) capacitação das partes interessadas para acessar, usar, adaptar e redistribuir REA; (2) desenvolvimento de políticas de apoio; (3) incentivo a REA de qualidade, inclusivos e equitativos; (4) fomento à criação de modelos de sustentabilidade para REA; e (5) facilitação da cooperação internacional (UNESCO, 2020c).

Compreende-se que tal publicação se faz importante nesse cenário de pandemia, em que o fechamento de instituições educacionais em diferentes países para conter a disseminação da COVID-19 está provocando mudanças na educação de muitos estudantes em todo o mundo. A UNESCO (2020b) está compartilhando em seu site algumas recomendações para permitir que o processo de ensino e aprendizagem continue sendo desenvolvido durante o momento de pandemia, como destaca o Quadro 1.

Quadro 1: Recomendações da UNESCO para o planejamento do ensino remoto.

\begin{tabular}{|l|l|}
\hline $\begin{array}{l}\text { Examinar a } \\
\text { disponibilidade e } \\
\text { escolher as } \\
\text { ferramentas mais } \\
\text { relevantes. }\end{array}$ & $\begin{array}{l}\text { Decidir sobre o uso de soluções de alta e baixa tecnologia, levando em consideração } \\
\text { a confiabilidade das fontes de alimentação locais, conectividade à internet e } \\
\text { habilidades digitais de professores e estudantes. O que pode acarretar na variação } \\
\text { de recursos, tais como, plataformas integradas de aprendizado digital, videoaulas, } \\
\text { Cursos On-line Abertos e Massivos (Massive Open Online Course - MOOC), } \\
\text { transmissão por rádios e TVs. }\end{array}$ \\
\hline $\begin{array}{l}\text { Garantir a inclusão } \\
\text { nos programas de } \\
\text { educação a distância. }\end{array}$ & $\begin{array}{l}\text { Implementar medidas para permitir que os estudantes, incluindo aqueles com } \\
\text { deficiência ou que possuem baixa renda, tenham acesso a programas de educação a } \\
\text { distância, se caso apenas um número limitado de discentes tiver acesso a } \\
\text { dispositivos digitais. }\end{array}$ \\
\hline $\begin{array}{l}\text { Proteger a } \\
\text { privacidade e a } \\
\text { segurança dos dados. }\end{array}$ & $\begin{array}{l}\text { Avaliar a segurança dos dados ao realizar upload e compartilhar informações ou } \\
\text { recursos educacionais nos espaços da Web com outras organizações ou pessoas. } \\
\text { Verificar se a utilização de aplicativos e plataformas não afeta de maneira negativa } \\
\text { a privacidade dos dados dos estudantes. }\end{array}$ \\
\hline $\begin{array}{l}\text { Priorizar soluções } \\
\text { para enfrentar os } \\
\text { desafios psicossociais } \\
\text { antes do ensino. }\end{array}$ & $\begin{array}{l}\text { Mobilizar as ferramentas disponíveis para conectar unidades educativas, } \\
\text { professores e estudantes entre si. Criar comunidades para oportunizar interações } \\
\text { humanas regulares, possibilitar medidas de assistência social e mencionar possíveis } \\
\text { desafios psicossociais que os discentes podem enfrentar quando estiverem isolados. }\end{array}$ \\
\hline $\begin{array}{l}\text { Planejar o } \\
\text { cronograma de } \\
\text { estudos dos }\end{array}$ & $\begin{array}{l}\text { Organizar discussões com as partes interessadas para verificar a possível duração } \\
\text { do fechamento da instituição e decidir se o programa de educação a distância deve } \\
\text { se concentrar no ensino de novos conhecimentos ou aprimorar o conhecimento dos } \\
\text { estudantes sobre as aulas anteriores. Planejar o cronograma, dependendo da situação }\end{array}$ \\
\hline
\end{tabular}




\begin{tabular}{|c|c|}
\hline $\begin{array}{l}\text { programas de } \\
\text { educação a distância. }\end{array}$ & $\begin{array}{l}\text { das zonas afetadas, do nível de estudos e das necessidades dos estudantes. Escolher } \\
\text { as metodologias de aprendizado apropriadas, considerando a questão de fechamento } \\
\text { de instituições educacionais e quarentenas em casa. }\end{array}$ \\
\hline $\begin{array}{l}\text { Prestar apoio a } \\
\text { professores no uso de } \\
\text { ferramentas digitais. }\end{array}$ & $\begin{array}{l}\text { Organizar breves sessões de capacitação e/ou orientação para docentes, caso houver } \\
\text { necessidade para desenvolver aulas. }\end{array}$ \\
\hline $\begin{array}{l}\text { Combinar abordagens } \\
\text { apropriadas e limitar } \\
\text { o número de } \\
\text { aplicativos e } \\
\text { plataformas. }\end{array}$ & $\begin{array}{l}\text { Combinar ferramentas ou mídias disponíveis para os discentes, favorecendo a } \\
\text { aprendizagem síncrona e assíncrona. Evitar sobrecarregar os estudantes, buscando } \\
\text { um equilíbrio na diversificação de aplicativos ou plataformas. }\end{array}$ \\
\hline $\begin{array}{l}\text { Desenvolver regras } \\
\text { de educação a } \\
\text { distância e monitorar } \\
\text { o processo de } \\
\text { aprendizado dos } \\
\text { estudantes. }\end{array}$ & $\begin{array}{l}\text { Definir regras com os discentes sobre a educação a distância. Criar perguntas, testes } \\
\text { ou exercícios formativos para o monitoramento do processo de aprendizado dos } \\
\text { estudantes. Buscar utilizar ferramentas para apoiar o envio de feedback dos alunos. }\end{array}$ \\
\hline $\begin{array}{l}\text { Definir a duração das } \\
\text { unidades de educação } \\
\text { a distância com base } \\
\text { nas habilidades de } \\
\text { autorregulação dos } \\
\text { estudantes. }\end{array}$ & $\begin{array}{l}\text { Manter um tempo coerente de acordo com o nível de autorregulação e habilidades } \\
\text { metacognitivas dos estudantes, especialmente para as aulas de transmissão ao vivo. }\end{array}$ \\
\hline $\begin{array}{l}\text { Criar comunidades e } \\
\text { aprimorar a conexão. }\end{array}$ & $\begin{array}{l}\text { Criar comunidades de docentes e gestores de instituições educativas para abordar o } \\
\text { sentimento de solidão ou desamparo, facilitando o compartilhamento de } \\
\text { experiências e a discussão sobre as possibilidades de estratégias para o } \\
\text { desenvolvimento da educação. }\end{array}$ \\
\hline
\end{tabular}

Fonte: adaptado de UNESCO (2020b).

A Organização para a Cooperação e Desenvolvimento Econômico (OCDE, 2020) é uma instituição intergovernamental, fundada em 1951, e tem o propósito de estimular o progresso econômico e o comércio internacional. No intuito de contribuir com a resposta educacional à pandemia, a OCDE elaborou um framework que apresenta a situação de vários países pelo mundo no enfrentamento da crise, com algumas diretrizes para apoiar a tomada de decisões neste período singular. O Ensino Superior não é tratado com exclusividade no relatório, ao invés disso há uma visão generalizada da educação e sua gestão. Destaca-se que as instituições de Educação Superior podem estabelecer parecerias com escolas como um meio para prover suporte adequado a professores e familiares, principalmente com relação à utilização de plataformas on-line.

O relatório apresenta um checklist com 25 ações práticas para uma resposta educacional à pandemia, a começar pela formação de uma força-tarefa ou comitê gestor que será responsável por desenvolver e implementar as práticas em cada contexto. Dentre o conjunto de praxes relatadas, evidencia-se o estabelecimento de mecanismos de coordenação junto às 
autoridades de saúde para sincronizar as ações e ajudar no avanço de metas de saúde pública; repensar os objetivos do currículo, definindo o que deveria ser aprendido neste período de isolamento social; estabelecer meios de atender os alunos que não tem acesso a dispositivos de conexão com a internet; e fortalecer a comunicação e colaboração dos estudantes para incentivar seu aprendizado mútuo e bem-estar.

O documento expõe a análise de um questionário on-line (survey) com 330 respostas de 98 países sobre como estão respondendo à crise educacional durante a pandemia. Apesar de uma porcentagem expressiva de participantes não terem reportado como seus governos ou redes educacionais agiram frente à crise, o documento aponta iniciativas de alguns países. Destaca-se aqui a atuação compartilhada referente à Itália e à França, respectivamente:

"O Ministério da Educação tem: criado páginas on-line, vídeos tutoriais e espaços de reuniões virtuais; oferecido plataformas de e-learning; criou uma força-tarefa de apoio; coordenou uma pluralidade de ações para desenvolver novos ambientes de aprendizagem; facilitou o uso de conteúdo digital e novos modelos de organização didática; forneceu aos professores treinamento remoto gratuito e ferramentas de atualização, também por meio de grupos de trabalho regionais; prestou assistência técnica às escolas; começou a monitorar iniciativas; introduziu formas de apoio econômico a estudantes desfavorecidos socioeconomicamente". "Tem sido estabelecida uma continuidade pedagógica para manter o contato entre estudantes e seus professores. Até o momento, os professores devem garantir, particularmente pelo uso de interfaces existentes (espaços de trabalhos digitais, email, ou recursos similares específicos de escolas privadas), que estudantes tenham acesso aos materiais do curso e sejam capazes de executar as tarefas e exercícios necessários para sua aprendizagem. Esse serviço de continuidade pedagógica pode ser baseado em uma plataforma de educação gratuita do Centro Nacional de Educação a Distância: 'My class at home' (Minha aula em casa). Este serviço oferece a possibilidade de executar aulas virtuais, enquanto mantêm a conexão entre colegas e professores" (OCDE, 2020, p. 12, tradução nossa).

O relatório também inclui os apontamentos das instituições respondentes do survey sobre quais são as prioridades educacionais mais relevantes ao momento. Foram destacadas questões como: "garantir a continuidade do trabalho pedagógico aos estudantes, apoiar os estudantes que não possuem habilidades para estudar de forma independente, garantir o bemestar dos estudantes, e prover suporte profissional aos professores e garantir seu bem-estar através de atenção médica" (p. 15, tradução nossa). As duas primeiras questões também foram elencadas como as prioridades mais difíceis de serem atendidas. O survey conclui apontando algumas mudanças causadas pela crise que surtiram efeitos educacionais positivos. A introdução de tecnologias e outras soluções inovadoras, o aumento da autonomia dos discentes para gerirem sua própria aprendizagem, e o fortalecimento do envolvimento e cooperação dos pais foram as questões de maior concordância.

Em relatório publicado em abril o Banco Mundial (2020) afirma que mais de 220 milhões de estudantes de nível superior foram afetados pelo fechamento de instituições, o 
que representa $13 \%$ do total de discentes impactados ao redor do mundo. Na América Latina e Caribe estes números passam de 27 milhões de estudantes universitários. O documento expõe um panorama dos desafios que têm se imposto às instituições de educação superior durante a pandemia e qual a realidade em que muitas delas podem se encontrar, como o adoecimento de acadêmicos e colaboradores, a evasão massiva de discentes, e a utilização de plataformas digitais limitadas e desatualizadas.

O Quadro 2 explicita as considerações do relatório sobre as ações imediatas no que se refere ao desenvolvimento remoto dos cursos.

Quadro 2: Considerações do Banco Mundial sobre o desenvolvimento dos cursos.

Treinar instrutores sobre como ensinar remotamente, adaptando o treinamento para permitir que cada membro da equipe acadêmica defina seu próprio plano de conteúdo, objetivos e avaliação de aprendizado dentro da nova modalidade;

Buscar e adaptar plataformas remotas existentes, onde a criação de novos cursos on-line fora do modelo presencial tradicional de instrução não é factível;

Pesquisar os alunos sobre sua capacidade de se envolver no aprendizado remoto - equipamentos, responsabilidades familiares, ambiente doméstico etc. - para entender o quão realista é para os estudantes se adaptarem aos planos de entrega dos instrutores, e sua capacidade de participar do ensino a distância;

Treinar e apoiar os alunos sobre como aprender remotamente;

Fornecer hardware para estudantes e instrutores, sempre que possível;

Determinar uma política institucional para avaliar o desempenho atual do aluno;

Determinar uma política institucional para avaliações do ensino e dos cursos;

Revisar e determinar requisitos de graduação para este ano acadêmico (2019-2020);

Avaliar a adequação da provisão de apoio financeiro e material para discentes e instituições em risco;

Desenvolver e implementar um programa para manter envolvidos os estudantes em risco, inclusive por meio de tutores e programas de trabalho personalizados.

Fonte: adaptado de Banco Mundial (2020, p. 4-5, tradução nossa).

O documento ainda aponta algumas dificuldades tecnológicas a serem antecipadas pelos sistemas de Ensino Superior. A inequidade da conectividade é a primeira delas, muitos acadêmicos dependem fortemente dos recursos institucionais por não possuírem hardware ou conexões estáveis de internet em suas casas. A capacidade dos professores de desenvolverem suas aulas de forma remota é outro fator importante, pois muitos docentes não haviam trabalhado remotamente e precisam de suporte pedagógico e técnico. Muito estudantes enfrentam a mesma dificuldade, aprender on-line exige a superação de inúmeros desafios que só serão identificados por meio de diálogos e feedback.

O Instituto Internacional para a Educação Superior na América Latina e Caribe (IESALC, 2020) é um órgão ligado à UNESCO responsável por monitorar os sistemas educacionais da região. Em relatório publicado em 13 de maio de 2020 sobre a COVID-19 e seus impactos na Educação Superior, são apontados os efeitos da pandemia, as políticas 
públicas, as respostas institucionais e um marco referencial para enfrentamento da crise. Estima-se que mais de $98 \%$ da população total de estudantes e professores universitários foram afetados pelo fechamento de instituições superiores na América Latina. A situação é agravada pelas profundas desigualdades sociais e econômicas presentes na região, o que dificulta a adesão das comunidades acadêmicas à forma remota de condução das atividades.

De acordo com o documento, "a falta de referência sobre crises semelhantes do passado dificulta a previsão sobre o que pode ocorrer em um futuro imediato" (p. 15, tradução nossa), porém os efeitos presentes são facilmente documentáveis. De acordo com recente pesquisa do instituto, as principais dificuldades de estudantes de nível superior na América Latina se diferenciam do resto do mundo.

Gráfico 1: Principais dificuldades dos estudantes universitários durante a pandemia

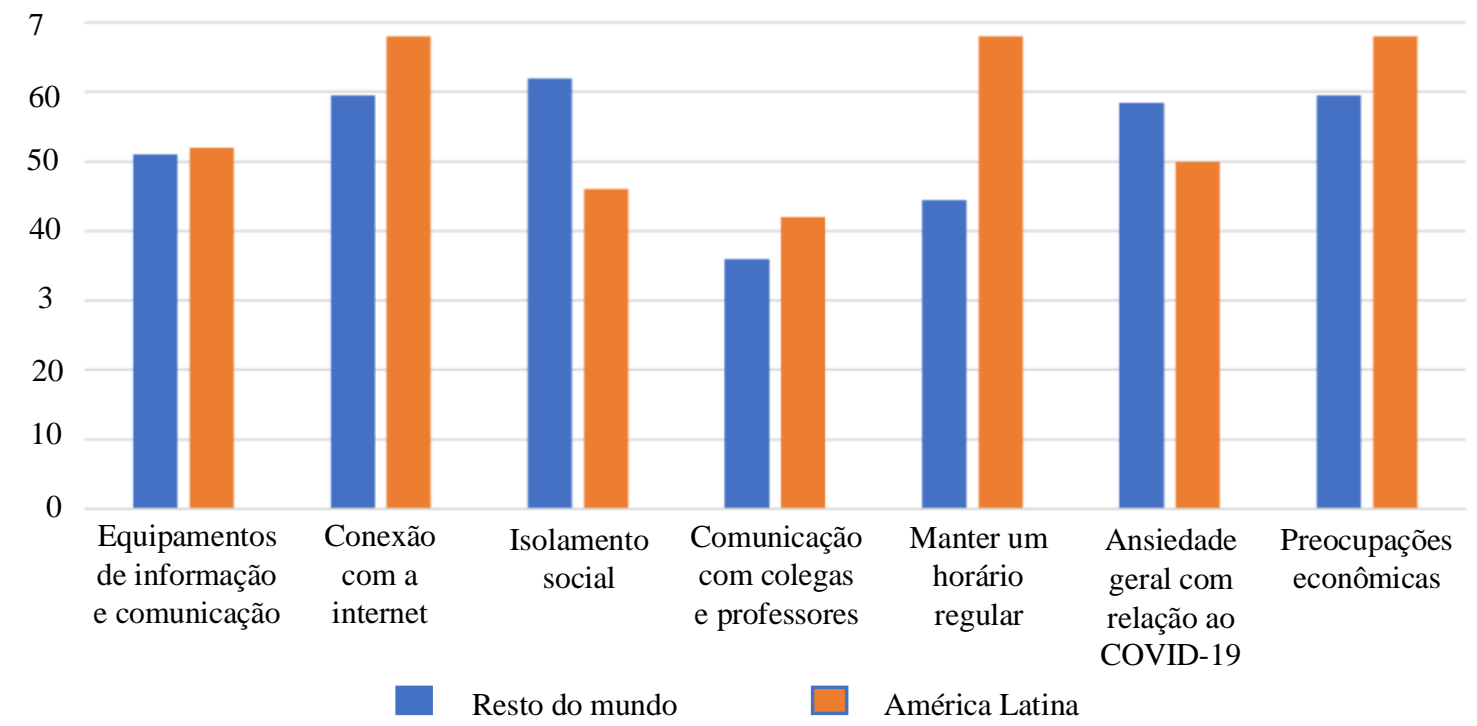

Fonte: adaptado de IESALC (2020, p. 15).

Como observado no Gráfico 1, os resultados sugerem que, em escala global, as principais preocupações são referentes ao isolamento social, às questões financeiras, à conectividade com a internet e, em geral, à situação de ansiedade relacionada à pandemia. Na América Latina, além das preocupações com a conexão à internet e questões financeiras, os discentes destacam dificuldades de conseguirem manter horário regular de estudos, denotando a necessidade de adaptação e autonomia frente aos estudos remotos.

Em relação ao apoio à continuidade formativa, é exposto que o princípio orientador fundamental para a ação do poder público nos assuntos educacionais tem sido o de "fazer todo o possível para garantir a continuidade da atividade docente, o que resultou em diferentes iniciativas em três frentes distintas: as plataformas, a capacitação de professores e conteúdo digital" (IESALC, 2020, p. 36, tradução nossa). Contudo, como o próprio 
levantamento aponta, nem todas as instituições têm sido capazes de seguir com projetos pedagógicos remotos. Visualizando o contexto brasileiro, o documento traz que:

"até o final de abril, aproximadamente um quarto dos estudantes não tinham totalmente garantida a continuidade de sua aprendizagem. Destes, $13 \%$ dos estudantes não tinham nenhum tipo de provisão mais de um mês após a declaração da pandemia. A situação se agrava quando as Instituições de Ensino Superior são comparadas por categoria administrativa: enquanto $97 \%$ das instituições privadas contavam com um sistema de ensino a distância que abrangia todos os cursos, no caso das públicas, apenas 39\%" (IESALC, 2020, p. 40, tradução nossa).

O relatório analisado ainda expõe um marco referencial detalhado para a saída da crise, estabelecendo suas fases e prioridades. Em síntese, o documento aponta que as ações passam por continuar a desenvolver práticas pedagógicas remotas, garantindo a prestação dos serviços na ausência de possibilidades presenciais; reabrir, no sentido de retomar as atividades presencias com as limitações impostas pelos órgãos de saúde; e reestruturar os processos de ensino e aprendizagem, incluindo abordagens híbridas e refletindo sobre as lições aprendidas durante o período de crise.

Vale salientar que a UNESCO, através do site da Coalizão Global da Educação ${ }^{2}$, a $\mathrm{OCDE}^{3}$, e o Banco Mundial ${ }^{4}$, buscaram organizar listas de recursos educacionais disponíveis na web que podem auxiliar acadêmicos, professores e instituições de ensino na continuidade de seus projetos pedagógicos.

No mesmo sentido, a Associação Internacional de Universidades (IAU) disponibilizou, em sua página na $w^{5} b^{5}$, um $h u b$ de informações sobre os desafios e respostas da Educação Superior a COVID-19. No site desta Associação é possível encontrar uma vasta gama de informações, das mais variadas fontes, sobre recomendações de enfrentamento à crise, monitoramento do impacto da pandemia nos sistemas educacionais, materiais de suporte à educação a distância, reportagens de diversos países do mundo e indicação de webinars.

Além disso, a IAU possui documentos próprios sobre os impactos da COVID-19 nas instituições superiores de todo o mundo. Um trabalho de grande abrangência foi publicado em maio de 2020 e traz os resultados de um survey global com 424 IES situadas em 109 países. O percentual de participantes da pesquisa por região se configura em $15 \%$ das Américas, $17 \%$ da Ásia \& Pacífico, 21\% da África e 46\% da Europa (IAU, 2020).

Dentre as questões analisadas nesse levantamento, têm-se uma atenção específica sobre os impactos da COVID-19 nos processos de ensino e aprendizagem. 
Gráfico 2: Como a COVID-19 afetou o ensino e aprendizagem

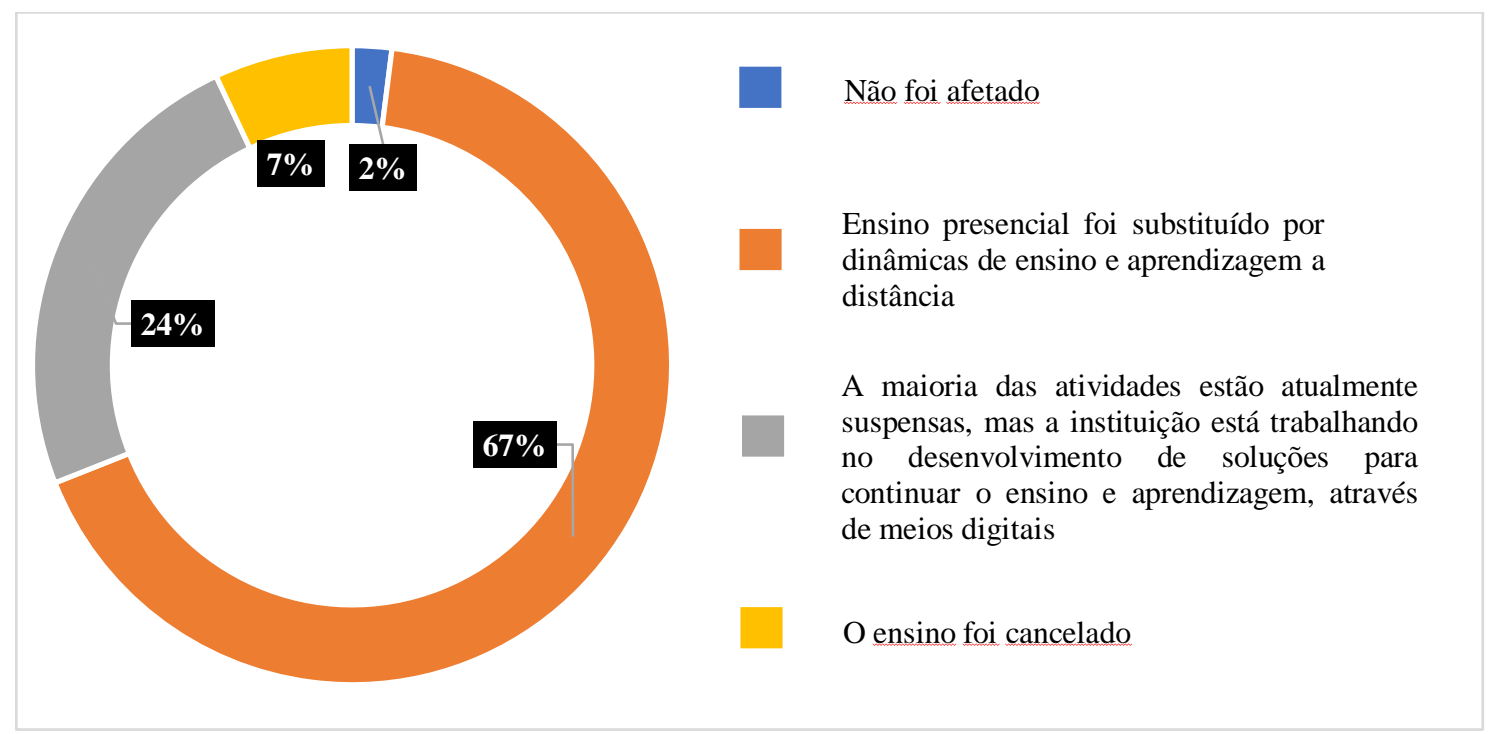

Fonte: adaptado de IAU (2020, p. 23).

Observa-se, na leitura do Gráfico 2, que mais da metade das instituições respondentes afirmaram ter substituído o ensino presencial por dinâmicas de ensino e aprendizagem a distância. Porém, como apontado pelo estudo, esses dados podem estar superestimados por conta das dificuldades dessa transição, que podem ser de ordem de acessibilidade e infraestrutura técnica, competências e pedagogias do ensino a distância, e do campo de estudo. No que se refere à primeira dimensão destacada pelo levantamento, pôde-se observar que há instituições que não moveram suas atividades para ambientes on-line porque identificaram que grande parte de seus alunos têm acesso à internet apenas na universidade, situação recorrente em países subdesenvolvidos. Porém, mesmo em países onde esse acesso é garantido, há instituições que não deram continuidade a suas atividades por não possuírem infraestrutura e ferramentas técnicas necessárias para viabilizar o ensino a distância. "Algumas instituições referiram implicações financeiras no investimento de ferramentas e licenças on-line" (IAU, 2020, p. 25).

Sobre o desenvolvimento do ensino a distância, grande parte das IES expressam que, apesar de não poderem garantir o mesmo nível de qualidade visto em situações "normais", ainda é melhor do que deixarem estudantes desatendidos. O estudo relata que:

"Muitos respondentes veem a experiência de trabalharem e ensinarem a distância como uma importante oportunidade de aprender com essa situação excepcional e propor possibilidades de aprendizagem mais flexíveis, explorar metodologias mistas ou híbridas e misturar ensino síncrono e assíncrono" (IAU, 2020, p. 26). 
A terceira, e última dimensão que impacta no seguimento das atividades pedagógicas, é referente as áreas de estudo que depende da utilização de estruturas físicas e equipamentos específicos não disponíveis nos ambientes domésticos. "Medicina, medicina veterinária, e várias disciplinas que dependem de acesso a laboratórios foram alguns dos exemplos fornecidos pelos respondentes onde a prática não pode ser substituída pelo ensino e aprendizagem a distância" (IAU, 2020, p. 25).

Outra fonte de informações relevante, presente no $h u b$ da IAU, se refere ao site da Educause $^{6}$, que disponibiliza uma página específica com o intuito de auxiliar as Instituições de Educação Superior a dinamizar o planejamento do trabalho educativo on-line, devido à interrupção do exercício pedagógico presencial nos campi causada pela COVID-19. No portal indicado é possível acessar uma variedade de tópicos informativos, contendo contribuições relevantes para o contexto da Educação Superior. Dentre eles, cabe destacar o tópico referente ao "Suporte e orientação ao Ensino Superior durante a COVID-19: Ensino, aprendizagem e suporte ao aluno". Este tópico corresponde ao documento denominado "Higher Ed Guidance During COVID-19: Teaching, Learning \& Student Support", elaborado por Laura Pasquini (2020). Em decorrência da pandemia, os docentes do sistema presencial de educação precisam desenvolver habilidades para fazer a transição do seu ensino e para prestar suporte ao estudante em um ambiente on-line. Desse modo, Pasquini (2020) apresenta algumas dicas para possibilitar que serviços educacionais sejam ofertados e estejam acessíveis a todos os envolvidos no processo educativo, conforme Quadro 3.

Quadro 3: Dicas de acessibilidade no ensino on-line

\begin{tabular}{|l|l|}
\hline $\begin{array}{l}\text { Descrição de texto } \\
\text { para arquivos de } \\
\text { imagens. }\end{array}$ & $\begin{array}{l}\text { Usuários com perda visual podem não ser capazes de ver fotos, imagens, ou capturas } \\
\text { de tela, mas podem ler a descrição textual usando tecnologia assistiva. }\end{array}$ \\
\hline $\begin{array}{l}\text { Selecionar e/ou criar } \\
\text { materiais de vídeos } \\
\text { com legendas } \\
\text { corretas e } \\
\text { transcrições textuais. }\end{array}$ & $\begin{array}{l}\text { Este recurso beneficia a todos na medida em que oferece múltiplas formas de acesso } \\
\text { anformação. Para estudantes com perda auditiva este recurso é altamente } \\
\text { recomendado. Ainda, isso ajuda se estudantes não conseguem executar ou ouvir um } \\
\text { vídeo ou arquivo de áudio por estarem em um ambiente barulhento. }\end{array}$ \\
\hline $\begin{array}{l}\text { Usar títulos } \\
\text { significativos ao } \\
\text { organizar ambientes } \\
\text { virtuais de } \\
\text { aprendizagem e } \\
\text { nomear arquivos e } \\
\text { atividades. }\end{array}$ & $\begin{array}{l}\text { Leitores de tela identificam títulos, sua ordem, e características de estilo. O material } \\
\text { elaborado por Pasquini, apresenta diretrizes gerais de design de acessibilidade } \\
\text { quem utiliza o Canvas como seu sistema de gestão de aprendizagem, além de dicas } \\
\text { para produção de documentos acessíveis para deficientes visuais no Microsoft } \\
\text { Word, facilitando a leitura por meio de softwares especializados. }\end{array}$ \\
\hline $\begin{array}{l}\text { Utilizar cores com } \\
\text { altos níveis de } \\
\text { contraste e outros } \\
\text { recursos para mostrar } \\
\text { informações nos } \\
\text { materiais de ensino. }\end{array}$ & $\begin{array}{l}\text { Para indivíduos com baixa percepção de contraste de cores ou que são daltônicos é } \\
\text { um desafio decifrar e ler certos materiais. Usar uma variedade de texturas, rótulos, } \\
\text { visuais. Pasquini sugere uma ferramenta gratuita de análise de contraste }{ }^{8} \text { para ajudar } \\
\text { a identificar cores apropriadas para texto e fundos quando se } \text { proma } \\
\text { apresentação ou página na web. }\end{array}$ \\
\hline
\end{tabular}




\begin{tabular}{|l|l|}
\hline $\begin{array}{l}\text { Utilizar frases } \\
\text { significativas para } \\
\text { links e hyperlinks. }\end{array}$ & $\begin{array}{l}\text { Não há necessidade de utilizar links inteiros como } \\
\text { 'https://onlinelearningconsortium.org/' e não é apropriado usar 'clique aqui' para } \\
\text { guiar os estudantes para websites. A forma acessível de incluir este link seria: } \\
\text { Online Learning Consortium (através de um hyperlink). Os leitores de tela } \\
\text { costumam ler todos os caracteres e pontuação listados em um link e, geralmente, } \\
\text { examinam uma página da web extraindo listas de links. Isso significa que 'clique } \\
\text { aqui' fornece aos alunos sem visão muito pouca informação e contexto para o que } \\
\text { pode fazer parte de cada link. }\end{array}$ \\
\hline $\begin{array}{l}\text { Verificar o acesso } \\
\text { dos seus alunos à } \\
\text { tecnologia e } \\
\text { conectividade. }\end{array}$ & $\begin{array}{l}\text { Pense em como e onde os estudantes acessarão o curso e/ou o site de serviços } \\
\text { discentes. Lembre-se de que nem todo o conteúdo criado pode ser acessado por } \\
\text { vários dispositivos, plataformas etc. Os alunos podem estar usando apenas um } \\
\text { smartphone ou não ter uma conexão wi-fi ou computador - por isso, é importante } \\
\text { criar itens que podem ser baixados. }\end{array}$ \\
\hline
\end{tabular}

Fonte: adaptado de Pasquini (2020).

O repositório construído pela Associação Brasileira de Educação Internacional (FAUBAI), também indicado no $h u b$ da IAU, coleta informações em nível nacional sobre o progresso de medidas, recomendações e avanços científicos para combater a pandemia. Ao observar o repositório COVID-19 FAUBAI $^{9}$, percebeu-se que diante da situação de pandemia as Instituições de Educação Superior brasileiras preocuparam-se em desenvolver várias ações para manter a qualidade do processo de ensino e de aprendizagem. No Quadro 4, estão registrados alguns exemplos sobre a questão referida.

Quadro 4: Medidas de enfrentamento à pandemia em universidades brasileiras.

\begin{tabular}{|l|l|}
\hline UNIVERSIDADE & \multicolumn{1}{c|}{ MEDIDAS } \\
\hline $\begin{array}{l}\text { Universidade } \\
\text { Camtadual de }\end{array}$ & $\begin{array}{l}\text { Suspendeu, no dia 12 de março, as atividades de ensino presencial da universidade. } \\
\text { Após quatro dias, a Reitoria divulgou um programa emergencial para os cursos e } \\
\text { disciplinas tanto de graduação, quanto de Pós-gradução, com o objetivo de } \\
\text { preservar as atividades acadêmicas do primeiro semestre de 2020, adaptando o } \\
\text { planejamento para o semestre, como calendário de atividades ou avaliação, e } \\
\text { readequar disciplinas teóricas e experimentais. }\end{array}$ \\
\hline $\begin{array}{l}\text { Universidade Federal } \\
\text { de Juiz de Fora } \\
\text { (UFJF). }\end{array}$ & $\begin{array}{l}\text { A Diretoria de Relações Internacionais (DRI) se mobilizou para dar suporte aos } \\
\text { estudantes, docentes e pesquisadores que estavam em mobilidade internacional, por } \\
\text { meio da criação de um projeto de suporte para comunidade acadêmica no exterior. } \\
\text { Para tanto, a plataforma Skype foi selecionada como via de comunicação. O projeto } \\
\text { visou amparar a comunidade acadêmica no exterior e, se houvesse necessidade, } \\
\text { encaminhar casos para setores de outras competências. Assim, questões acerca do } \\
\text { bem-estar físico e emocional, além do isolamento social imposto em alguns países, } \\
\text { e de repatriamento poderiam ser melhor discutidas. }\end{array}$ \\
\hline $\begin{array}{l}\text { Universidade Federal } \\
\text { do Pará (UFPA). }\end{array}$ & $\begin{array}{l}\text { Aniversidade antecipou a outorga de grau a acadêmicos, que estavam } \\
\text { matriculados no último período letivo dos cursos de Enfermagem e de Farmácia. A } \\
\text { outorga foi realizada em caráter excepcional, em conformidade com a Portaria } \\
\text { 383/2020 do Ministério da Educação, que dispõe sobre a antecipação da colação de } \\
\text { grau para os estudantes dos cursos de Medicina, Enfermagem, Farmácia e } \\
\text { Fisioterapia, como ação do combate à pandemia do novo coronavírus. }\end{array}$ \\
\hline
\end{tabular}




\begin{tabular}{|l|l|}
\hline $\begin{array}{l}\text { Universidade Federal } \\
\text { de Ciências da Saúde } \\
\text { de Porto Alegre } \\
\text { (UFCSPA). }\end{array}$ & $\begin{array}{l}\text { A Pró-Reitoria de Graduação (Prograd) passou a oferecer, a partir de 11 de maio, a } \\
\text { Série Webinars sobre Educação a Distância (EaD), direcionada ao corpo docente da } \\
\text { UFCSPA. A atividade faz parte do programa de formação de professores e visa } \\
\text { oportunizar estudos, discussões e instrumentalização sobre a educação a distância } \\
\text { na instituição. Os Webinars de Formação Docente sobre EaD se referem a diretrizes } \\
\text { para o planejamento de atividades na modalidade EaD; ferramentas para atividades } \\
\text { síncronas; ferramentas para atividades assíncronas; planejamento pedagógico; } \\
\text { planejamento de material didático; avaliação em EaD; ferramentas do Moodle; } \\
\text { produção de vídeo; conteúdo clínico em EaD; fontes de Recursos Educacionais } \\
\text { Abertos; direitos autorais; e metodologias ativas em EaD. }\end{array}$ \\
\hline $\begin{array}{l}\text { Pontifícia } \\
\begin{array}{l}\text { Universidade } \\
\text { Católica de São Paulo }\end{array}\end{array}$ & $\begin{array}{l}\text { A PUC-SP realizou palestras, por meio da plataforma Teams, voltadas para a a } \\
\text { docência on-line, contemplando estratégias pedagógicas para ambientes virtuais de } \\
\text { aprendizagem. }\end{array}$
\end{tabular}

Fonte: adaptado de FAUBAI (2020).

Além disso, a IAU compartilhou em seu site ações mencionadas no portal da Associação Europeia de Educação Internacional (EAIE), incluindo um conjunto de recomendações sobre como as Instituições de Educação Superior podem responder à COVID-19 (Quadro 5).

\section{Quadro 5: Recomendações da EAIE às Instituições de Ensino Superior}

Entrar em contato com seus estudantes nacionais e internacionais - especialmente os discentes dos países mais afetados pelo vírus - e garantir seu bem-estar; ser solidária e compreensiva, questionando a eles como estão suas famílias e amigos e encaminhá-los para os serviços de suporte apropriados disponíveis, dependendo de suas necessidades específicas. Alguns estudantes podem precisar de apoio, tal como assistência financeira, serviços de saúde e aconselhamento por sentirem-se angustiados;

Estabelecer políticas relacionadas aos programas de estudos no exterior, isto é, para programas que precisam ser cancelados, as instituições de Educação Superior devem entrar em contato com seus acadêmicos para explicar se o programa será adiado para uma data posterior ou cancelado. Cabe as instituições explicar como proceder com o processo de reembolso. Sob o princípio de força maior, os discentes devem ser reembolsados por todos os programas internacionais que precisaram ser cancelados;

Verificar a cobertura de seguro de saúde internacional para todos os seus acadêmicos que estão atualmente no exterior e os estudantes internacionais de sua instituição, caso for preciso acessar serviços de saúde enquanto estão no exterior, pois algumas apólices de seguro podem não ter cobertura para o coronavírus;

Estabelecer políticas relacionadas a viagens, isto implica dizer que enquanto algumas instituições proibiram todas as viagens, outras ainda precisam tomar uma decisão. Caso não tiver certeza a respeito de prosse guir com uma missão oficial no exterior ou com um programa de estudos no exterior, sugere-se verificar os avisos de viagem do seu governo;

Manter a sua comunidade atualizada sobre como a situação se desenvolve à luz da COVID-19, como por exemplo em relação à suspensão das aulas, o adiamento de viagens não cruciais ou o fornecimento de materiais informativos sobre o vírus. É de suma importância prover essas informações aos estudantes e funcionários em tempo hábil.

Fonte: adaptado de EAIE (2020).

O Ministério da Educação (MEC) brasileiro, órgão da administração federal, possui diversas áreas de competência, a saber: a política nacional de educação; a educação infantil; 
a educação em geral, compreendendo ensino fundamental, ensino médio, educação superior, educação de jovens e adultos, educação profissional e tecnológica, educação especial e educação a distância, com exceção do ensino militar; a avaliação, a informação e a pesquisa educacionais; a pesquisa e a extensão universitárias; o magistério e a assistência financeira a famílias consideradas carentes para a escolarização de seus filhos ou dependentes (BRASIL, 2020b).

No contexto pandêmico, o Ministério da Educação redigiu a Portaria no 343, em 17 de março de 2020, que dispôs sobre a substituição das aulas presenciais teórico-cognitivas por aulas em meios digitais enquanto durar a pandemia. Mais tarde, essa Portaria veio a sofrer alterações por novos dispositivos legais, ampliando as possibilidades de substituição de um espectro maior de atividades acadêmicas presenciais por atividades on-line equivalentes, incluindo, por exemplo, os estágios dos cursos de licenciaturas. Estas medidas se configuram como basilares para a continuidade dos projetos pedagógicos em curso nas instituições superiores.

$\mathrm{Na}$ ampliação do acesso à informação, o MEC disponibilizou uma ferramenta de acompanhamento das IES $^{10}$ que monitora ações de enfrentamento à COVID-19 e outras informações relevantes ao funcionamento das instituições. Em outra página no site do MEC é possível ver que medidas estão sendo tomadas pelo Ministério a nível federal durante a pandemia $^{11}$.

O Ministério da Educação aprovou o Parecer do Conselho Nacional de Educação (CNE) $\mathrm{N}^{\mathrm{o}}$ 5, de 28 de abril de 2020, que dispõe sobre a reorganização do calendário escolar e a possibilidade de cômputo de atividades não presenciais para fins de cumprimento da carga horária mínima anual, devido à pandemia da Covid-19 (BRASIL, 2020c). No tópico sobre a Educação Superior, este documento revela que existe uma tradição por parte do corpo docente de mediar o processo de ensino e aprendizagem fazendo uso de tecnologias digitais, tanto no ensino presencial quanto à distância.

Além disso, expressa que as Instituições de Ensino Superior, no exercício de autonomia e responsabilidade na condução de seus projetos acadêmicos, respeitando-se os parâmetros e normas legais estabelecidas, podem considerar a utilização da modalidade EaD como um meio para a organização pedagógica e curricular de seus processos de reposição das aulas. A partir desses apontamentos foram conduzidas algumas recomendações à Educação Superior, sintetizadas no Quadro 6.

Quadro 6: Recomendações do Parecer do CNE (No 5, de 28 de abril de 2020) à Educação Superior

Adotar a substituição de disciplinas presenciais por aulas não presenciais;

Adotar a substituição de atividades presenciais relacionadas à avaliação, processo seletivo, TCC e aulas de laboratório, por atividades não presenciais, considerando o modelo de mediação de tecnologias digitais de informação e comunicação adequado à infraestrutura e interação necessárias;

Regulamentar as atividades complementares, de extensão e o TCC;

Organizar o funcionamento de seus laboratórios e atividades preponderantemente práticas em conformidade com a realidade local; 
Adotar atividades não presenciais de práticas e estágios, especialmente aos cursos de licenciatura e formação de professores, extensíveis aos cursos de ciências sociais aplicadas e, onde couber, de outras áreas, informando e enviando à SERES ou ao órgão de regulação do sistema de ensino ao qual a IES está vinculada, os cursos, disciplinas, etapas, metodologias adotadas, recursos de infraestrutura tecnológica disponíveis às interações práticas ou laboratoriais a distância;

Adotar a oferta na modalidade a distância ou não presencial às disciplinas teórico-cognitivas dos cursos da área de saúde, independente do período em que são ofertadas;

Supervisionar estágios e práticas profissionais na exata medida das possibilidades de ferramentas disponíveis;

Definir a realização das avaliações de forma remota;

Adotar regime domiciliar para alunos que testarem positivo ou que sejam do grupo de risco;

Organizar processo de capacitação de docentes para o aprendizado à distância ou não presencial;

Implementar teletrabalho para professores e colaboradores;

Proceder o atendimento ao público dentro das normas de segurança editadas pelas autoridades públicas e com espeque em referências internacionais;

Divulgar a estrutura de seus processos seletivos de forma remota totalmente digital;

Reorganização dos ambientes virtuais de aprendizagem e outras tecnologias disponíveis nas IES para atendimento do disposto nos currículos de cada curso;

Realização de atividades on-line síncronas de acordo com a disponibilidade tecnológica;

Oferta de atividades on-line assíncronas de acordo com a disponibilidade tecnológica;

Realização de testes on-line ou por meio de material impresso entregues ao final do período de suspensão das aulas; e

Utilização de mídias sociais de longo alcance (WhatsApp, Facebook, Instagram etc.) para estimular e orientar os estudos e projetos.

Fonte: adaptado de Brasil (2020c, p. 18-19).

É importante ressaltar que o disposto neste parecer esclarece que as orientações para o desenvolvimento de atividades pedagógicas não presenciais e para reorganização dos calendários escolares trata-se de sugestões. Pois compreende-se que neste momento histórico, a inovação e criatividade das redes, instituições educacionais, docentes e estudantes podem oportunizar o surgimento de soluções mais adequadas. Para tanto, deve-se considerar os objetivos de aprendizagem e, também, o desenvolvimento das competências e habilidades a serem alcançados pelos acadêmicos diante das circunstâncias surgidas na pandemia. A CAPES não possui um site dedicado a divulgar iniciativas de combate à pandemia. Porém, algumas ações estão sendo reportadas, como a disponibilização de um curso de Recursos Educacionais Abertos a alunos do sistema da Universidade Aberta do Brasil (UAB) ${ }^{12}$.

Em síntese, por meio do corpus de análise foi possível perceber que as estratégias para a reorganização da Educação Superior no contexto local (brasileiro) e no contexto global (mundial), devido à problemática da pandemia do novo coronavírus, correspondem à realização de pesquisas, o que inclui os desafios que as Instituições de Educação Superior têm enfrentado para auxiliar no desenvolvimento do processo educativo e compartilhamento de soluções; lançamento de publicações contendo orientações sobre práticas educacionais aberta; compartilhamento de sites de recomendações para permitir que o processo de ensino 
e aprendizagem que era realizado no sistema presencial de educação possa continuar sendo desenvolvido a distância; sugestões de recursos digitais que podem auxiliar estudantes e professores em seus afazeres; informações sobre a criação de programas emergenciais para os cursos e disciplinas de graduação e de pós-graduação para as adaptações necessárias no decorrer do semestre letivo e, também, de projeto de suporte para comunidade acadêmica no exterior; formação docente sobre educação on-line, através de plataformas digitais; elaboração de políticas relacionadas aos programas de estudos e de viagens internacionais, e diretrizes de preparação para retomada das atividades presenciais.

Sendo assim, as ações desenvolvidas e compartilhadas pelos organismos multilateriais, órgãos de educação e demais instituições vinculadas a temáticas de educação (global e nacional), podem oportunizar aos gestores, professores e outros interessados a realização de leituras, reflexões, compartilhamentos e trocas de ideias a respeito de estratégias que podem contribuir para que o processo educativo ocorra via on-line de maneira eficiente, com qualidade, considerando a utilização de recursos digitais para favorecer o planejamento da prática pedagógica e a construção de aprendizagens, além de propiciar serviços de apoio voltados para o bem-estar e a saúde.

\section{Considerações finais}

A presença do novo coronavírus desencadeou mudanças e incertezas em todas as esferas da sociedade. No contexto educacional, as aulas que aconteciam presencialmente precisaram ser substituídas rapidamente por aulas remotas, devido ao desenvolvimento abrupto da pandemia e, com ela, a necessidade do distanciamento social como principal estratégia de prevenção.

Em virtude deste contexto, a pesquisa trata de sistematizar o que vem sendo recomendado por organismos multilaterais e associações internacionais e nacionais, bem como legislado no Brasil, na perspectiva de viabilizar que os processos educativos continuem em cenários remotos diversos daqueles presenciais tradicionais que não são possíveis em tempos pandêmicos. Para tanto, a pesquisa focou nos dados, nas recomendações e nas experiências descritas das fontes utilizadas, especialmente com relação às estratégias para a reorganização do Ensino Superior, no contexto global (mundial) e local (brasileiro), durante o período de pandemia de coronavírus (COVID-19).

No Ensino Superior, predominantemente, há a recomendação de construção de estratégias para continuidade das formações acadêmicas, com adaptação das aulas presenciais para o modelo de aulas remotas, com ênfase das possibilidades mediadas por tecnologias digitais, denominadas on-line (UNESCO, 2020b; OCDE, 2020; BANCO MUNDIAL, 2020; IESALC, 2020; Pasquine, 2020, BRASIL, 2020c). Cabe referir a diferença entre o desenvolvimento de cursos preparados para a modalidade de educação a distância, com organização antecipada e equipes de apoio para a elaboração de materiais multimodais e atividades de interação e avaliação, e as estratégias consideradas emergenciais de transposição da educação presencial para a educação on-line, que mesmo com orientações 
institucionais, ficam a cargo das adaptações possíveis realizadas em tempo real por cada docente (HODGES et al, 2020; BEHAR, 2020).

Os levantamentos realizados pela OCDE (2020) junto a 98 países, e pela IESALC (2020), no contexto da América Latina, além das informações agrupadas na FAUBAI (2020) referentes à IES brasileiras, demonstram a diversidade de estratégias institucionais implementadas no contexto pandêmico para continuidade das atividades educacionais. Por meio de uma análise mais detalhada dos documentos pesquisados, torna-se evidente que cada Instituição de Ensino Superior, de forma particular, precisa compreender seu contexto e construir, a partir dos recursos disponíveis e em diálogo com a sua comunidade, um plano próprio para minimizar os impactos da crise. Além da virtualização do ensino, suporte ao bem-estar acadêmico, às demandas acadêmico-administrativas, às atividades de pesquisa e de extensão, às práticas profissionais e à internacionalização, entre outros aspectos, precisa ser considerado pela Instituição de Ensino Superior em seu planejamento, dada a complexidade da composição da formação universitária.

Os docentes universitários precisam receber suporte didático e técnico, para que sejam capazes de fazer o melhor uso das ferramentas digitais disponíveis na web. Em relação à ação docente e à adequação dos processos pedagógicos, os documentos encontrados nos repositórios dos organismos multilaterais e nacionais apresentam recomendações explícitas, tais como a necessidade de oferecer capacitação docente e de orientar para produção de recursos educacionais abertos (UNESCO, 2020c), a urgência de reorganização dos processos pedagógicos e provimento de suporte profissional aos professores (OCDE, 2020), a importância de políticas governamentais para garantir equidade de acesso aos recursos tecnológicos e seus usos (IESALC, 2020), a atenção que os professores devem ter em relação aos requisitos de acessibilidade a ambientes e conteúdos digitais (Pasquine, 2020), bem como a discussão junto aos docentes sobre a readequação dos planos de ensino e dos objetivos de aprendizagem para o período (BANCO MUNDIAL, 2020; BRASIL, 2020c).

É necessário repensar os objetivos do currículo, definindo o que deve ser aprendido neste período de distanciamento social e como realizar as adequações metodológicas necessárias. Em um momento de grande ansiedade e incerteza para todos os integrantes das comunidades acadêmicas é preciso manter diálogo constante e estabelecer dinâmicas de cooperação para diminuir a sensação de isolamento.

Os estudantes precisam de acesso aos recursos necessários, de equipamento a acesso de dados, bem como de orientação técnica e de como manter seus estudos e as interações esperadas para seguir seu desenvolvimento. Dentre as recomendações expostas pelos organismos é clara a necessidade de elaborar práticas pedagógicas inclusivas, que atendam às necessidades dos diversos estudantes e ofereçam oportunidades de crescimento, desenvolvimento, permanência e êxito.

Por fim, entende-se que é de suma importância a colaboração entre Instituições de Educação Superior para que o desenvolvimento do processo de ensino e aprendizagem seja realizado com qualidade. Neste sentido, torna-se fundamental que todas as partes interessadas (gestores, professores, técnicos e estudantes) trabalhem conjuntamente para 
possibilitar que este nível educacional continue propiciando a construção de conhecimentos de maneira efetiva em um tempo marcado pela pandemia da COVID-19.

\section{Notas}

1. Link de acesso: https://en.unesco.org/covid19/educationresponse/globalcoalition

2. Link de acesso: https://en.unesco.org/covid19/educationresponse/solutions

3. Link de acesso: http://www.oecd.org/education/Supporting-the-continuation-of-teaching-and-learning-during-thecovid-19-pandemic.pdf

4. Link de acesso: http://documents.worldbank.org/curated/en/964121585254860581/pdf/Remote-Learning-DistanceEducation-and-Online-Learning-During-the-COVID19-Pandemic-A-Resource-List-by-the-World-Banks-EdtechTeam.pdf

5. Link de acesso: https://www.iau-aiu.net/COVID-19-Higher-Education-challenges-and-responses

6. Link de acesso: https://library.educause.edu/topics/information-technology-management-and-leadership/covid-19

7. Link de acesso: https://community.canvaslms.com/docs/DOC-2060-general-accessibility-design-guidelines

8. Link de acesso: https://developer.paciellogroup.com/resources/contrastanalyser/

9. Link de acesso: http://faubai.org.br/pt-br/repositorio-covid/

10. Link de acesso: http://portal.mec.gov.br/coronavirus/

11. Link de acesso: https://www.gov.br/mec/pt-br/assuntos/noticias/coronavirus-saiba-quais-medidas-o-mec-ja-realizouou-estao-em-andamento

12. Link de acesso: https://www.capes.gov.br/36-noticias/10299-uab-oferece-curso-de-recursos-educacionais-abertos

\section{Referências}

BANCO MUNDIAL. The COVID-19 Crisis Response: Supporting tertiary education for continuity, adaptation, and innovation. 2020b. Disponível em: http://pubdocs.worldbank.org/en/621991586463915490/WB-Tertiary-Ed-and-Covid-19-Crisis-for-publicuse-April-9.pdf. Acesso em: 20 de maio 2020.

BEHAR, Patrícia Alejandra. Artigo: O Ensino Remoto Emergencial e a Educação a Distância - Coronavírus. Jornal da Universidade Federal do Rio Grande do Sul, Porto Alegre, 06 jul. de 2020. Disponível em: <https://www.ufrgs.br/coronavirus/base/artigo-o-ensino-remoto-emergencial-e-a-educacao-a-distancia/>. Acesso em: 5 nov. 2020.

BRASIL. Ministério da Educação. Gabinete do Ministro. Portaria nº 343, de 17 de março de 2020. Dispõe sobre a substituição das aulas presenciais por aulas em meios digitais enquanto durar a situação de pandemia do Novo Coronavírus - COVID-19. Diário Oficial da União, Brasília, DF, 18 mar. 2020a. p. 39.

BRASIL. Ministério da Educação. Institucional. 2020b. Disponível em: http://portal.mec.gov.br/component/content/article?id=32681:apresentacao. Acesso em: 05 nov. 2020.

BRASIL. Ministério da Educação. Parecer $\mathrm{CNE} \mathrm{CPN}^{\circ}$ 5, de 28 de abril de 2020. Dispõe sobre a reorganização do Calendário Escolar e da possibilidade de cômputo de atividades não presenciais para fins de cumprimento da carga horária mínima anual, em razão da Pandemia da COVID-19. Brasília: Ministério da Educação, Conselho Nacional de Educação, 2020c. Disponível em: http://portal.mec.gov.br/index.php?option=com_docman\&view=download\&alias=145011-pcp00520\&category_slug=marco-2020-pdf\&Itemid=30192 Acesso em: 04 nov. 2020. 
BRASIL. Ministério da Saúde. Sobre a doença Coronavírus (COVID-19). Disponível em: https://coronavirus.saude.gov.br/sobre-a-doenca. Acesso em: 12 maio 2020.

CAPES - Coordenação de Aperfeiçoamento de Pessoal de Nível Superior. Saiba como se prevenir do novo coronavírus. 2020. Disponível em: https://capes.gov.br/36-noticias/10214-saiba-como-se-prevenir-donovo-coronavirus. Acesso em: 12 maio 2020.

EAIE - European Association for International Education. 2020. How higher education institutions can respond to COVID-19. Disponível em: https://www.eaie.org/blog/how-higher-education-institutionsrespond-covid-19.html. Acesso em: 01 jun. 2020.

EDUCAUSE. Higher Ed Support \& Guidance During COVID-19: Teaching, Learning \& Student Support. Disponível em: https://library.educause.edu/resources/2020/3/higher-ed-support-and-guidance-duringCOVID19. Acesso em: 31 maio 2020.

FAUBAI - Associação Brasileira de Educação Internacional. Repositório COVID-19 FAUBAI. 2020. Disponível em: http://faubai.org.br/pt-br/repositorio-COVID/. Acesso em: 31 maio 2020.

GIL, Antonio Carlos. Como elaborar projetos de pesquisa. 6. ed. São Paulo: Atlas, 2018.

HODGES, Charles; MOORE, Stephanie; LOCKEE, Barb; TRUST, Torrey; BOND, Aaron. The Difference Between Emergency Remote Teaching and Online Learning. EDUCAUSE, 27 de mar. de 2020. Disponível em: https://er.educause.edu/articles/2020/3/the-difference-between-emergency-remote-teaching-andonline-learning. Acesso em: 04 jun. 2020.

IAU - International Association of Universities. The Impact of COVID-19 on Higher Education Around the World: IAU Global Survey Report. Disponível em: https://www.iauaiu.net/IMG/pdf/iau_covid19_and_he_survey_report_final_may_2020.pdf. Acesso em: 05 nov. 2020.

IESALC - Instituto Internacional para la Educación Superior en América Latina y el Caribe. COVID-19 y educación superior: De los efectos inmediatos al día después. Disponível em: http://www.iesalc. unesco.org/wp-content/uploads/2020/05/COVID-19-ES-130520.pdf. Acesso em: 04 jun. 2020.

MORGADO, José Carlos; SOUSA, Joana; PACHECO, José Augusto. Transformações educativas em tempos de pandemia: do confinamento social ao isolamento curricular. Práxis Educativa, v. 15, p. 1-10, 2020.

OCDE - Organização para a Cooperação e Desenvolvimento Econômico. A framework to guide an education response to the COVID-19 Pandemic of 2020. 2020a. Disponível em: https://read.oecdilibrary.org/view/?ref=126_126988-t631xosohs\&title=A-framework-to-guide-an-education-response-tothe-COVID-19-Pandemic-of-2020. Acesso em: 04 jun. 2020.

OPAS - Organização Pan-Americana da Saúde. Folha informativa - COVID-19 (doença causada pelo novo coronavírus). 2020. Disponível em: https://www.paho.org/bra/index.php?option=com_content\&view= article\&id=6101:COVID19\&Itemid=875. Acesso em: 12 maio 2020.

PASQUINI, Laura. Higher Ed Guidance During COVID-19: Teaching, Learning \& Student Support. 2020. Disponível em:

https://docs.google.com/document/d/1Zea87K6PbK8e-tLDERzgsnn2NkUqiEuay7JiMh9EQ0/edit\#heading=h.788il6r0zf5x. Acesso em: 31 maio 2020.

PONTES, Fernanda Rodrigues; ROSTAS, Márcia Helena Sauaia Guimarães. Precarização do trabalho do docente e adoecimento: COVID-19 e as transformações no mundo do trabalho, um recorte investigativo. Revista Thema, v. 18, p. 278-300, 2020.

UNESCO - Organização das Nações Unidas para a Educação, a Ciência e a Cultura. Coalizão Global da Educação. 2020a. Disponível em: https://pt.unesco.org/COVID19/globaleducationcoalition. Acesso em: 12 maio 2020.

UNESCO - Organização das Nações Unidas para a Educação, a Ciência e a Cultura. COVID-19: 10 recomendações para planejar soluções de ensino a distância. 2020b. Disponível em: 
https://en.unesco.org/news/Covid-19-10-recommendations-plan-distance-learning-solutions. Acesso em: 12 maio 2020.

UNESCO - United Nations Educational, Scientific and Cultural Organization. Guidance on Open Educational Pratices during COVID-19 pandemic. 2020c. Disponível em: https://iite.unesco.org/wpcontent/uploads/2020/05/Guidance-on-Open-Educational-Practices-during-School-Closures-EnglishVersion-V1_0.pdf. Acesso em: 26 maio 2020.

UNESCO - United Nations Educational, Scientific and Cultural Organization. The SDG-Education 2030 Steering Committee Recommendations for COVID-19 Education Response. 2020d. Disponível em: https://sdg4education2030.org/sites/default/files/2020-04/SDG-

Education\%202030\%20SC\%20recommendations\%20-\%20COVID-19\%20education\%20response.pdf. Acesso em: 20 maio 2020.

YIN, Robert K. Pesquisa qualitativa do início ao fim. Porto Alegre: Penso, 2016.

\section{Correspondência}

Karen Graziela Weber Machado: É Doutoranda em Educação pelo Programa de Pós-Graduação da Pontifícia Universidade Católica do Rio Grande do Sul - PUCRS e pesquisadora do Grupo de Pesquisa Interdisciplinar em Tecnologias Digitais, Internacionalização e Permanência Estudantil (GeTIPE). O presente trabalho foi realizado com apoio da Coordenação de Aperfeiçoamento de Pessoal de Nível Superior - Brasil (CAPES), por meio de concessão de bolsa para a realização do doutorado da autora.

E-mail: karengraziela@gmail.com

Felipe Sereno Soso: É Licenciado em Física pela Universidade de Passo Fundo (2017), Mestrando em Educação pela Pontifícia Universidade Católica do Rio Grande do Sul, tem seus estudos financiados pela empresa UOL Edtech, pesquisa sobre as temáticas de tecnologias digitais, permanência no ensino superior e educação a distância.

E-mail: felipe.soso@edu.pucrs.br

Adriana Justin Cerveira Kampff: É Diretora de Graduação; Professora Permanente do Programa de PósGraduação em Educação; Professora Colaboradora do Programa de Pós-Graduação em Educação em Ciências e Matemática - Pontifícia Universidade Católica do Rio Grande do Sul - PUCRS.

E-mail: adriana.kampff@pucrs.br

Texto publicado em Currículo sem Fronteiras com autorização dos autores 